\title{
COMPARISON OF CLINICAL AND MAMMOGRAPHIC FINDINGS IN BENIGN BREAST DISEASE
}

\author{
Bhate Jidnyasa $T^{1}$, Kulkarni Prachi $S^{2}$
}

${ }_{1}^{1}$ Assistant Professor, Department of General Surgery, BJ Government Medical College, Pune, Maharashtra, India. ${ }^{2}$ Assistant Professor, Department of General Surgery, BJ Government Medical College, Pune, Maharashtra, India.

\section{BACKGROUND}

\section{ABSTRACT}

Although, incidence of benign breast disease is 4 - 5 times that of breast malignancy, their diagnosis and treatment has received little attention. Mammography, sonomammography and Fine Needle Aspiration Cytology (FNAC) together as diagnostic modalities provide a viable solution to the problem.

\section{MATERIALS AND METHODS}

All the patients included in this study underwent a mammogram and ultrasonography with FNAC. FNAC was used as gold standard, against which mammography was compared. An observational study design was used for the purpose of this study. A case report method was adopted. Both prospective and retrospective data spanning 2 years was used.

\section{RESULTS}

In this study, both clinical and mammographic diagnoses were concurrent in $33(55 \%)$ of the patients that were examined. On application of Chi-square test, this was found to be statistically significant at $\mathrm{p}=0.05$. A concordance of diagnosis (Mammography, sonomammography and Fine Needle Aspiration Cytology (FNAC)) was achieved for fibroadenoma in 14 of 15 patients (93.33\%) for fibroadenosis in 8 of 19 patients (42.11\%) and fibrocystic change in 11 of 26 patients (42.31\%) examined.

\section{CONCLUSION}

Radiomammography is a sensitive investigation for the diagnosis of benign breast disease. Clinical and mammographic findings correlate well in the diagnosis of benign breast disease.

\section{KEY WORDS}

Mammography, Sonomammography, FNAC: Fine Needle Aspiration Cytology.

HOW TO CITE THIS ARTICLE: Jidnyasa BT, Prachi KS. Comparison of clinical and mammographic findings in benign breast disease. J. Evolution Med. Dent. Sci. 2018;7(31):3485-3490, DOI: 10.14260/jemds/2018/785

\begin{abstract}
BACKGROUND
Benign breast diseases are responsible for significant morbidity and are of great concern to the patient. Although, incidence of benign breast disease is 4 - 5 times that of breast malignancy, their diagnosis and treatment has received little attention.1-9 Majority of benign breast lesions are not associated with an increased risk of subsequent breast cancer. Hence, there is a need to avoid unnecessary surgical procedures in these patients. ${ }^{2-8}$ Mammography, sonomammography and Fine Needle Aspiration Cytology (FNAC) together as diagnostic modalities provide a viable solution to the problem.10,11 Comparability of clinical and radiologic findings could prove to be benchmarks in further effective management of benign breast diseases. It is important for clinicians to recognise benign lesions, to both distinguish them from malignancy as well as establish the most appropriate treatment modality for each case. ${ }^{12}$
\end{abstract}

\section{Aims and Objectives}

1. To study sensitivity and specificity of mammography in diagnosis of benign breast disease.

'Financial or Other Competing Interest': None.

Submission 02-07-2018, Peer Review 16-07-2018,

Acceptance 19-07-2018, Published 30-07-2018.

Corresponding Author:

Dr. Kulkarni Prachi $S$

\#87/3A, Shree Colony,

Kothrud, Pune-411038,

Maharashtra, India.

E-mail: prachi_avin@rediffmail.com

DOI: $10.14260 /$ jemds $/ 2018 / 785$
2. To study sensitivity and specificity of Ultrasonography in diagnosis of benign breast disease.

3. Correlation of clinical and mammography findings in benign breast disease.

\section{MATERIALS AND METHODS}

It is a descriptive study. 60 women patients were selected as a part of this study using the following inclusion and exclusion criteria.

\section{Inclusion Criteria}

- Only women were included in the study.

- Patients with complaints of-

- Palpable breast lumps.

- Breast pain.

- Heaviness of breasts.

- Nipple discharge.

- Unilateral/ bilateral symptoms.

\section{Exclusion Criteria}

- Pre-pubertal, post-menopausal women.

- Inflammatory breast lesions- Breast abscess, mastitis required immediate intervention in the form of drainage of the abscess or treatment with antibiotic regimen. Any subsequent investigations would have led to a distortion of mammographic appearance of the disease.

- Clinical and FNAC evidence of malignancy.

- $\quad$ Lactating mothers.

The data was collected under the following headings using a yes/ no type response for recording the findings. 
Radiological Investigations used-

- Mammography

- Craniocaudal view.

- Mediolateral oblique view

- Ultrasonography.

\section{Confirmation of Diagnosis}

Fine Needle Aspiration Cytology (FNAC).

FNAC findings.

\section{These were as follows-}

1. Fibroadenoma.

2. Cysts, complex cysts.

3. Benign dysplasia, apocrine metaplasia.

\section{Diagnostic Criteria}

For the purpose of this study, fibrocystic breast disease was considered as two separate entities-

1. Fibroadenosis, i.e. without cystic changes.

2. Fibrocystic changes (FCC), i.e. with cystic changes.

\section{Clinical Diagnosis}

For each of the following at least 3 of the characteristics were required to be present to make a clinical diagnosis.

1. Fibroadenoma- all the following criteria need to be fulfilled.
a. Discrete lump.
b. Non-tender.
c. Freely mobile.
d. Soft/ firm in consistency.

2. Fibroadenosis (without cystic changes)-

a. Tender/ non-tender breast nodularity.

b. Tender/ non-tender lump.

c. Lump if palpable- firm consistency.

d. Nipple discharge present.

e. Tender palpable lymph nodes present/ absent.

3. Fibrocystic change
a. Lump- firm in consistency.
b. Intermediate mobility.
c. Nipple discharge may/may not be present.
d. Breast pain may/may not be present.

\section{Mammographic Diagnosis}

To reach a mammographic diagnosis, the following criteria were used-

- Fibroadenoma.

1. Coarse calcification.

2. Spherical/ well-demarcated.

- $\quad$ Fibroadenosis (Without cystic change).

1. Scattered calcifications (Not coarse).

2. Hypodense lesions.

- Fibrocystic changes (FCC)

1. Coarse calcifications present/ absent.

2. Eggshell/ layered calcifications.

\section{Ultrasonography of Breast (Sonomammography) Diagnosis}

For making sonomammographic diagnoses the following criteria were used-

\section{Fibroadenoma-}

a. Well-demarcated margins.

b. Hypoechoic lesions.
2. Fibroadenosis (without cystic changes)-

1. Increased breast density.

2. Absence of cysts.

3. Fibrocystic changes (FCC)-

1. Cysts.

2. Increased breast density.

\section{FNAC Diagnosis}

FNAC sample was taken from affected side, where discrete lump was present or from site of diffuse nodularity.

Mammography and sonomammography were conducted prior to FNAC sampling. Where cysts were isolated on sonomammography USG-guided FNAC was conducted in the absence of discrete lump.

\section{Diagnosis}

1. Benign hyperplasia- fibroadenoma.

2. Benign dysplasia- fibroadenosis.

3. Apocrine metaplasia, cysts- fibrocystic change.

Although an extensive classification is made on basis of histopathological appearances, in this study only three groups were identified based on FNAC diagnosis. Any further histopathological classification would have necessitated use of core-needle biopsy or excision biopsy, which was outside the scope of this study.

\section{Methods}

It is a descriptive study. Mammography is a special type of Xray imaging used to create a detailed image of the breast. It is used to look for different types of tumours and cysts. In this study, we utilised the following diagnostic equipment.

All the patients included in this study underwent a mammogram and ultrasonography of the breast here using the following equipment and methodology.

\section{Equipment: Siemens Mammomat $\mathbf{3 0 0 0}$}

- Opdose: Optimises x-ray dose and image quality.

- Opcomp: Determines the optimum degree of compression needed to produce uniform tautness, based on individual breast characteristics.

- Stereotactic biopsy attachment.

- Radiation dose- $0.7 \mathrm{mSv}$.

Mammography could detect lesions as small as 0.5 centimetres ( 0.2 inches). Lumps that could be felt were at least 1 centimetre $(0.4$ inches).

\section{Mammography (Radiomammography)}

Mammograms used doses of ionising radiation to create this image. Radiologists then analysed the image for any abnormal growths. Wavelength of x-rays (Mo-K) used were longer than those used for radiography of bones.

\section{Ultrasonography (Sonomammography)}

The ultrasound test works on the principle of sending and receiving high-frequency sound waves to create images of internal organs or tissues. Sound waves pass through the tissues of the area being examined. These sound waves were recorded and displayed on a computer screen or televisiontype monitor or printed out for review. They were useful to help differentiate fluid-filled lumps from solid lumps. 
An observational study design was used for the purpose of this study.

A Case Report Method was adopted

Both prospective and retrospective data spanning 2 years was used.

Statistical Methods used for Analysis were

Chi-square test; sensitivity and specificity calculations.

FNAC was used as gold standard, against which mammography was compared for sensitivity and specificity calculations.

\section{RESULTS}

\begin{tabular}{|c|c|}
\hline Age Group & No. of Patients (\%) \\
\hline $11-20$ & $4(6.66)$ \\
\hline $21-30$ & $5(8.33)$ \\
\hline $31-40$ & $17(28.33)$ \\
\hline $41-50$ & $28(46.66)$ \\
\hline $51-60$ & $6(10)$ \\
\hline Total & $\mathbf{6 0}$ \\
\hline Table 1. As per Age Groups \\
\hline
\end{tabular}

\begin{tabular}{|c|c|}
\hline OC Pill Consumption & No. of Patients (\%) \\
\hline Yes & $5(8.33)$ \\
\hline No & $41(68.33)$ \\
\hline No contraception & $14(23.33)$ \\
\hline Total & $\mathbf{6 0}$ \\
\hline \multicolumn{2}{|c|}{ Table 2. Method of Contraception } \\
\hline
\end{tabular}

\begin{tabular}{|c|c|}
\hline Nipple Discharge & No. of Patients (\%) \\
\hline Greenish & $5(8.33)$ \\
\hline Milky & $5(8.33)$ \\
\hline Serous & $8(13.33)$ \\
\hline Yellowish & $3(5)$ \\
\hline None & $39(65)$ \\
\hline Total & $\mathbf{6 0}$ \\
\hline Table 3. Colour of the Nipple Discharge \\
\hline
\end{tabular}

\begin{tabular}{|c|c|}
\hline Sonomammography & $\begin{array}{c}\text { No. of Patients } \\
\text { (\%) }\end{array}$ \\
\hline Cysts & $16(26.66)$ \\
\hline Hypoechoic & $27(45)$ \\
\hline Normal & $13(21.66)$ \\
\hline Complex cyst & $2(3.33)$ \\
\hline Anechoic lesions & $2(3.33)$ \\
\hline Total & $\mathbf{6 0}$ \\
\hline Table 4. Different types of Lesions detected by \\
Ultrasonography \\
\hline
\end{tabular}

\begin{tabular}{|c|c|}
\hline Mammographic Diagnosis & $\begin{array}{c}\text { No. of Patients } \\
\text { (\%) }\end{array}$ \\
\hline Fibroadenoma & $14(23.33)$ \\
\hline Fibroadenosis & $8(13.33)$ \\
\hline Fibrocystic change & $24(40)$ \\
\hline Benign-inconclusive & $14(23.33)$ \\
\hline Total & $\mathbf{6 0}$ \\
\hline Table 5. Mammographic diagnoses Reached \\
\hline
\end{tabular}

FNAC Diagnosis

\begin{tabular}{|c|c|}
\hline FNAC Diagnosis & No. of Patients (\%) \\
\hline Fibroadenoma & $15(25)$ \\
\hline Fibroadenosis & $19(31.66)$ \\
\hline
\end{tabular}

\begin{tabular}{|c|c|}
\hline Fibrocystic change & $24(40)$ \\
\hline Total & $\mathbf{6 0}$ \\
\hline Table 6. Confirmatory FNAC Diagnoses \\
\hline
\end{tabular}

Comparison Findings

\begin{tabular}{|c|c|c|c|c|}
\hline \multirow{3}{*}{$\begin{array}{l}\text { Mammograph } \\
\text { ic Diagnosis }\end{array}$} & \multicolumn{3}{|c|}{ Clinical Diagnosis } & \multirow{3}{*}{ 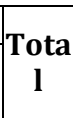 } \\
\hline & Fibroadenom & Fibroadenosi & Fibrocysti & \\
\hline & $\mathbf{a}$ & $\mathbf{s}$ & c & \\
\hline Yes & 14 & 8 & 11 & 33 \\
\hline No & 4 & 23 & 0 & 27 \\
\hline Total & 18 & 31 & 11 & 60 \\
\hline \multicolumn{5}{|c|}{ mographic Diagnosis } \\
\hline
\end{tabular}

\begin{tabular}{|c|c|c|c|c|}
\hline \multirow{2}{*}{$\begin{array}{c}\text { FNAC } \\
\text { Diagnosis }\end{array}$} & \multicolumn{3}{|c|}{ Clinical Diagnosis } & \multirow{2}{*}{} \\
\cline { 2 - 5 } & Fibroadenoma Fibroadenosis & $\begin{array}{c}\text { Fibrocystic Total } \\
\text { Change }\end{array}$ & \\
\hline Yes & 15 & 18 & 11 & 44 \\
\hline No & 3 & 13 & 0 & 16 \\
\hline Total & $\mathbf{1 8}$ & $\mathbf{3 1}$ & $\mathbf{1 1}$ & $\mathbf{6 0}$ \\
\hline \multicolumn{4}{|c|}{ Table 8. Clinical v/s FNAC Diagnosis } \\
\hline
\end{tabular}

\begin{tabular}{|c|c|c|c|c|}
\hline \multirow{2}{*}{\begin{tabular}{|c|} 
FNAC \\
Diagnosi \\
$\mathrm{s}$
\end{tabular}} & \multicolumn{3}{|c|}{ Mammographic Diagnosis } & \multirow[b]{2}{*}{ Total } \\
\hline & Fibroadenoma & Fibroadenosis & $\begin{array}{c}\text { Fibrocystic } \\
\text { Change }\end{array}$ & \\
\hline Yes & 14 & 8 & 24 & 46 \\
\hline No & 1 & 11 & 2 & 14 \\
\hline Total & 15 & 19 & 26 & 60 \\
\hline \multicolumn{5}{|c|}{ Table 9. Mammography v/s FNAC Diagnosis } \\
\hline
\end{tabular}

\begin{tabular}{|c|c|c|c|}
\hline \multirow{2}{*}{$\begin{array}{c}\text { Mammographic } \\
\text { Diagnosis }\end{array}$} & \multicolumn{2}{|c|}{ Mammographic Density } & \multirow{2}{*}{ Total } \\
\cline { 2 - 3 } & Increased & Normal & \\
\hline Yes & 23 & 23 & 46 \\
\hline No & 11 & 3 & 14 \\
\hline Total & $\mathbf{3 4}$ & $\mathbf{2 3}$ & $\mathbf{6 0}$ \\
\hline Table 10. Effect of Mammographic Breast Density on \\
Mammographic Diagnosis \\
\hline
\end{tabular}

\begin{tabular}{|c|c|c|c|}
\hline Concordant Diagnosis & Yes & No & Total \\
\hline Fibroadenoma & 14 & 1 & 15 \\
\hline Fibroadenosis & 8 & 11 & 19 \\
\hline Fibrocystic change & 11 & 15 & 26 \\
\hline Total & $\mathbf{3 3}$ & $\mathbf{2 7}$ & $\mathbf{6 0}$ \\
\hline \multicolumn{3}{|c|}{ Table 11. Disease-Wise Concordance } \\
\hline
\end{tabular}

Sensitivity and Specificity of Diagnostic Modalities for Diagnosis of Benign Breast Diseases

\section{Mammography}

\begin{tabular}{|c|c|c|c|}
\hline & \multicolumn{3}{|c|}{ Mammographic Diagnosis } \\
\hline FNAC & Fibroadenoma & Total \\
\hline & Yes & No & \\
\hline Yes & 14 & 0 & 14 \\
\hline No & 1 & 45 & 46 \\
\hline Total & $\mathbf{1 5}$ & $\mathbf{4 5}$ & $\mathbf{6 0}$ \\
\hline \multicolumn{4}{|c|}{ Table 12. For Fibroadenoma } \\
\hline
\end{tabular}

\begin{tabular}{|c|c|c|c|}
\hline & \multicolumn{3}{|c|}{ Mammographic Diagnosis } \\
\hline FNAC & Fibroadenosis & Total \\
\hline & Yes & No & 19 \\
\hline Yes & 8 & 11 & 41 \\
\hline No & 0 & 41 & $\mathbf{6 0}$ \\
\hline Total & $\mathbf{8}$ & $\mathbf{5 2}$ & \\
\hline \multicolumn{4}{|c|}{ Table 13. For Fibroadenosis } \\
\hline
\end{tabular}




\begin{tabular}{|c|c|c|c|}
\hline & \multicolumn{3}{|c|}{ Mammographic Diagnosis } \\
\hline FNAC & Fibrocystic Change & Total \\
\hline & Yes & No & \\
\hline Yes & 24 & 2 & 26 \\
\hline No & 0 & 34 & 34 \\
\hline Total & $\mathbf{2 4}$ & $\mathbf{3 6}$ & $\mathbf{6 0}$ \\
\hline \multicolumn{4}{|c|}{ Table 14. For Fibrocystic Change } \\
\hline
\end{tabular}

\begin{tabular}{|c|c|c|c|}
\hline & \multicolumn{2}{|c|}{ USG Diagnosis } & \\
\hline FNAC & Fibroadenoma & Total \\
\hline & Yes & No & \\
\hline Yes & 14 & 1 & 15 \\
\hline No & 0 & 45 & 45 \\
\hline Total & 14 & 46 & 60 \\
\hline \multicolumn{4}{|c|}{ Table 15. For Fibroadenoma } \\
\hline
\end{tabular}

\begin{tabular}{|c|c|c|c|}
\hline & \multicolumn{2}{|c|}{ USG Diagnosis } & \\
\hline FNAC & Fibrocystic Changes & Total \\
\hline & Yes & No & \\
\hline Yes & 24 & 2 & 26 \\
\hline No & 0 & 34 & 34 \\
\hline Total & $\mathbf{2 4}$ & $\mathbf{3 6}$ & $\mathbf{6 0}$ \\
\hline \multicolumn{4}{|c|}{ Table 16. For Fibrocystic Change } \\
\hline
\end{tabular}

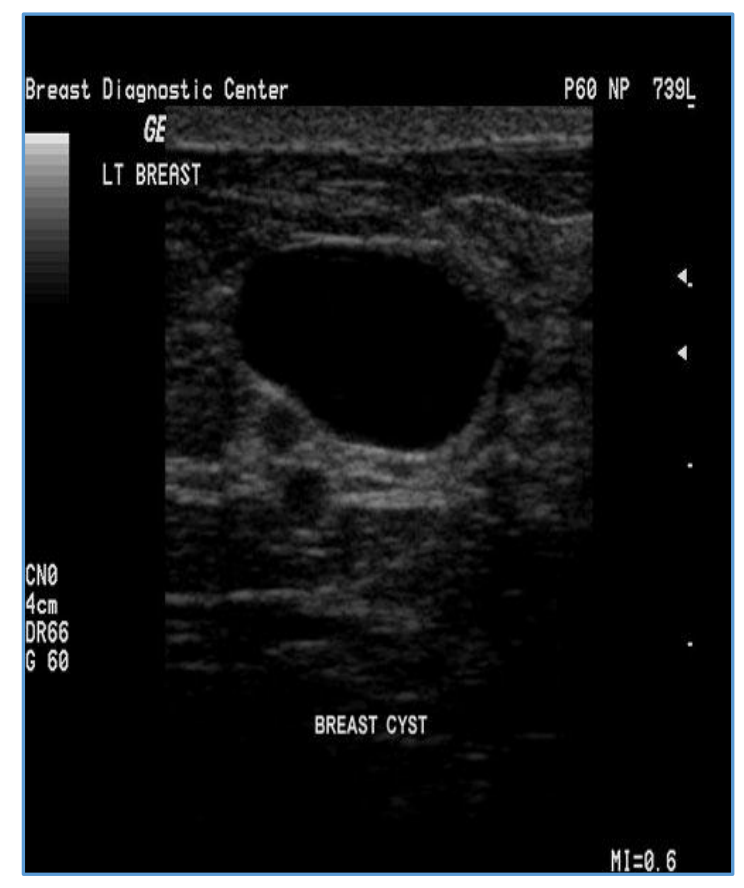

Breast Cyst on Sonomammography

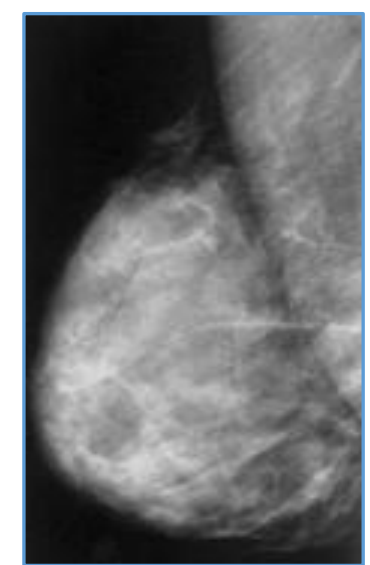

Mammography: Mediolateral- Oblique (MLO) View

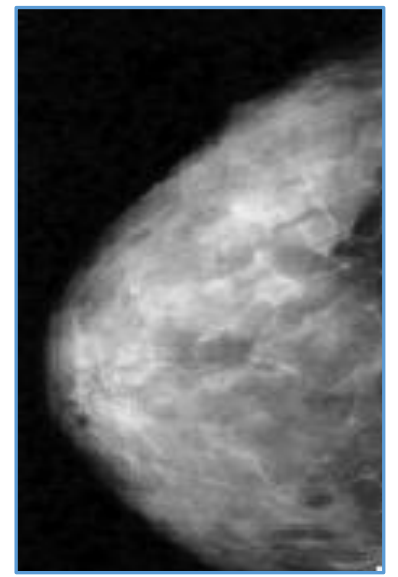

Mammography: Craniocaudal (CC) View

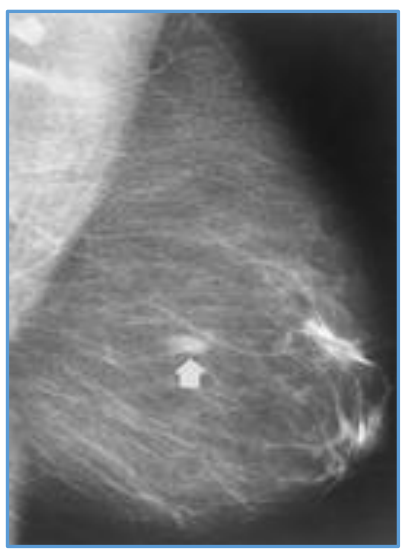

Mammography: Coarse Calcifications in MLO View

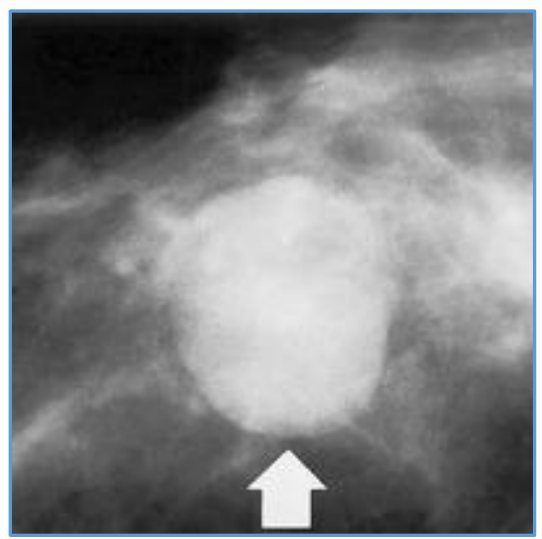

Mammography: Hyperdense Lesion: breast cyst

\section{DISCUSSION}

Maximum numbers of patients with benign breast disease were in the age group of 41 - 50 years, i.e. 28 (46.66\%). Minimum no. of patients was in the age group of $21-30$ years, i.e. $4(6.66 \%)$.

Incidence of benign breast disease in patients who consumed OC pills was $5(8.33 \%)$ as compared to 41 $(68.33 \%)$ in patients who used other methods of contraception and $14(23.33 \%)$ in those who did not use any form of contraception. 21 (35\%) of the patients had nipple discharge on examination. 
Of these 5 (8.33\%) patients had greenish nipple discharge, $5(8.33 \%)$ patients had milky nipple discharge, 8 (13.33\%) had serous nipple discharge and 3 (5\%) had yellowish nipple discharge.

Based on these findings the following clinical diagnoses were reached. $18(30 \%)$ of the patients had fibroadenoma, 31 (51.66\%) of the patients had fibroadenosis and 11 (18.33\%) of the patients had fibrocystic changes.

Cysts were identified in $18(30 \%)$ of the patients on Radiomammography. 7 (11.66\%) of the patients had cyst in right breast, 4 (6.66\%) of the patients had cyst in left breast, $7(11.66 \%)$ of the patients had cysts in both the breasts. In 32 $(53.33 \%)$ of the patients, no cysts were identified on mammography.

\section{Mammography Diagnoses}

Based on both mammography diagnoses were reached as follows:

- $14(23.33 \%)$ of the patients had fibroadenoma.

- $8(13.33 \%)$ of the patients had fibroadenosis.

- $24(40 \%)$ of the patients had fibrocystic changes.

- $14(23.33 \%)$ of the patients returned benigninconclusive findings.

\section{FNAC Diagnosis}

The following FNAC diagnoses were reached:

- $15(25 \%)$ of the patients had fibroadenoma.

- $19(31.66 \%)$ of the patients had fibroadenosis.

- $24(40 \%)$ of the patients had fibrocystic changes.

In $2(3.33 \%)$ of the patients, a definitive FNAC diagnosis could not be reached. They were classified as benign inconclusive.

\section{Disease-Wise Distribution}

On clinical diagnosis, 31 (51.66\%) of the patients had fibroadenosis, 11 (18.33\%) had fibrocystic change and 18 (30\%) had fibroadenoma.

\section{Age-Wise distribution of Mammographic Diagnosis}

Maximum number of patients with fibrocystic change were observed to be in the age group of $41-50$ years, i.e. 11 (18.33\%). Total number of mammographic diagnoses of benign breast disease were made in the age group of 41 - 50 years, i.e. 29 (48.33\%).

of the patients with past history of benign breast disease maximum clinical diagnoses were made of fibroadenosis i.e. 13 (21.66\%), maximum mammographic diagnoses were made of fibrocystic changes i.e. $9(15 \%)$. A concordance of diagnosis was reached in $8(13.33 \%)$ of the cases. Only in 46 (76.66\%) patients could a definitive diagnosis be reached. In the remaining 14 (23.33\%), a definitive mammographic diagnosis could not be reached. They were termed benigninconclusive. $24(40 \%)$ of the patients were diagnosed to have fibrocystic changes on mammography.

\section{Comparative Findings}

\section{Clinical Diagnosis v/s Mammographic Diagnosis}

Both clinical and mammographic diagnoses were concurrent in 33 (55\%) of the patients that were examined. On application of Chi-square test, this was found to be statistically significant at $p=0.05$. The probability of this event occurring by chance being less than 0.001 .

\section{Clinical Diagnosis v/s FNAC Diagnosis}

Both clinical and FNAC diagnoses were concurrent in 44 (73.33\%) of the patients that were examined. On application of the Chi-square test, this was found to be statistically significant at $p=0.05$. The probability of this event occurring by chance being 0.013 .

\section{Mammographic v/s FNAC Diagnosis}

Sensitivity of mammographic diagnosis (Radiomammographic) for diagnosing fibroadenoma is $93.33 \%$, fibroadenosis is $100 \%$ and that for fibrocystic changes is $100 \%$. Overall, sensitivity is $97.77 \%$.

Specificity of mammographic diagnosis for diagnosing fibroadenoma is $100 \%$, fibroadenosis is $78.84 \%$ and for fibrocystic change is $94.44 \%$. Overall specificity is $91.09 \%$.

Mammographic and FNAC diagnoses were concurrent in $46(76.66 \%)$ of the patients. On application of Chi-square test, this was found to be statistically significant at $p=0.05$. The probability of this event occurring by chance being less than 0.001 .

\section{Sonomammography Diagnosis v/s FNAC Diagnosis}

Sensitivity of sonomammographic diagnosis for diagnosing fibroadenoma is $100 \%$, fibroadenosis is $100 \%$ and that for fibrocystic changes is $100 \%$. Overall, sensitivity is $100 \%$. Specificity of mammographic diagnosis for diagnosing fibroadenoma is $97.82 \%$, fibroadenosis is $80.39 \%$ and for fibrocystic change is $80.95 \%$. Overall specificity was $86.38 \%$.

This was found to be better than that seen in the 1993 Ishii $M$ study,13,14 which had a sensitivity of $93.2 \%$ and specificity of $85.9 \%$.

\section{Comparative Findings as per Disease-Wise Distribution}

In those patients who had a palpable lump, a mammographic diagnosis was reached in 34 (60) patients. Of these, 15 patients had fibrocystic change. A concordant diagnosis was reached in 26 (60) patients. Maximum concordance was for the diagnosis of fibroadenoma in 14 (60) patients.

In patients who showed cysts on mammography (24), fibrocystic changes were diagnosed in 18 patients.

In patients who had increased mammographic breast density, a concordant diagnosis could be achieved in only 17 (34) patients.

Patients who had Coarse Calcifications on Mammography Of the patients who were diagnosed to have fibroadenosis on mammography 6 (8) had coarse calcifications and coarse calcifications were seen in 6 (24) patients who had fibrocystic change.

\section{Concordant Diagnosis}

Concordance of diagnosis considered when all three i.e. clinical, mammographic and FNAC diagnoses are in agreement; they are the same. This was compared against the total diagnoses of the same disease.

FNAC was considered as the confirmatory test for this study. This was done in view of findings of the 1995 Turnbull LS and Smith PA et al study. ${ }^{15}$

Of the 60 patients examined, a concordant diagnosis was achieved in 33 patients. Of these, 11 had fibrocystic change.

A concordance of diagnosis was achieved for fibroadenoma in 14 of 15 patients (93.33\%), for 
fibroadenosis in 8 of 19 patients (42.11\%) and fibrocystic change in 11 of 26 patients (42.31\%) examined.

\section{CONCLUSION}

Radiomammography is a sensitive investigation for the diagnosis of benign breast disease. Sonomammography is a specific investigation for diagnosis of benign breast disease, especially fibrocystic changes. Clinical and mammographic findings correlate well in the diagnosis of benign breast disease. OC pills may play an important role in preventing benign breast disease. Although, mammography is a costly investigation in the Indian setting, it is sensitive in detecting benign breast disease. Therefore, it merits consideration of its use in patients in whom there is clinically significant suspicion of benign breast disease.

\section{Recommendations}

- Patients with clinical history of benign breast disease should undergo a baseline mammogram.

- Patients with fibrocystic changes (clinically) should undergo sonomammography in addition to mammogram.

- Women in child-bearing age group, OC pills may be offered as a prophylactic option.

- Wherever financially feasible, both mammogram and sonomammogram should be offered to the symptomatic patient.

- This investigation is also recommended to screen patients with high risk of benign or malignant breast disease.

\section{REFERENCES}

[1] Iyer SP, Gore MA. Epidemiology of benign breast diseases in females in child bearing age group. Bombay Hosp Journal 2000;42(1):141-46.

[2] Caleffi M, Filho DD, Borghetti K, et al. Cryoablation of benign breast tumors: evolution of technique and technology. Breast 2004;13(5):397-407.

[3] Kelsey JL, Gammon MD. Epidemiology of breast cancer. Epidemiol Rev 1990;12:228-40.

[4] Cole P, Elwood MJ, Kaplan SD. Incidence rates and risk factors of benign breast neoplasms. Am J Epidemiol 1978;108(2):112-20.
[5] Hutchinson WB, Thomas DB, Hamlin WB, et al. Risk of breast cancer in women with benign breast disease. J Natl Cancer Inst 1980;65(1):13-20.

[6] Fitzgibbons PL, Henson DE, Hutter RV. Benign breast changes and the risk for subsequent breast cancer: an update of the 1985 consensus statement. Cancer Committee of the College of American Pathologists. Arch Pathol Lab Med 1998;122(12):1053-5.

[7] Sarnelli R, Squartini F. Fibrocystic condition and "at risk" lesions in asymptomatic breasts: a morphologic study of postmenopausal women. Clin Exp Obstet Gynecol 1991;18(4):271-9.

[8] Cook MG, Rohan TE. The patho-epidemiology of benign proliferative epithelial disorders of the female breast. J Pathol 1985;146(1):1-15.

[9] Donegan WL. Common benign conditions of the breast. In: Donegan WL, Spratt JS, eds. Cancer of the Breast. $5^{\text {th }}$ edn. St. Louis, MO: Saunders 2002: p. 67-110.

[10] Shaaban AM, Sloane JP, West CS, et al. Histopathologic types of benign breast lesions and risk of breast cancer. Am J Surg Pathol 2002;26(4):421-30.

[11] Morrow M. Pre-cancerous breast lesions: implications for breast cancer prevention trials. Int J Radiat Oncol Biol Phys 1992;23(5):1071-8.

[12] Freeman M. Imaging: new techniques. In: Harris JR, Lippman ME, Morrow M, et al. eds. Diseases of the Breast. $3^{\text {rd }}$ edn. Philadelphia, Pa: Lippincott Williams \& Wilkins 2004:p. 181-98.

[13] Ishii M. Ultrasonographic diagnoses of breast diseases: a review of diagnostic criteria of sonomammography on real-time scanner. Nihon Igaku Hoshasen Gakkai Zasshi 1993;53(10):1141-59.

[14] Stavros AT, Thickman D, Rapp CL, et al. Solid breast nodules: use of sonography to distinguish between benign and malignant lesions. Radiology 1995;196(1):123-34.

[15] Green B, Dowley A, Turnbull LS, et al. Impact of fineneedle aspiration cytology, ultrasonography and mammography on open biopsy rate in patients with benign breast disease. BJS 1995;82(11):1509-11. 